\title{
Raising The Level Of Abstraction In Online Education: The Context
}

\author{
Samuel M. Natale, (E-mail: sammymn@aol.com), Adelphi University, \\ Anthony F. Libertella, Adelphi University \\ Sebastian A. Sora, Adelphi University \\ John Ulin, Adelphi University
}

\begin{abstract}
A commonly accepted definition of online learning is that students have access to learning experiences in: time, place, pace, learning style, content, assessment, and pathways (Chen, 2003). Although this is true, there is a considerable concern about the level of abstraction involved in online education. Critics of flexible learning call it just another fad (Zemsky \& Massy, 2004). These criticisms are founded in claims that online learning failed to launch a pedagogical revolution or attract students in masses. Further, some argue that it is a training and not educational tool. With all the buzz of successes and failures, flexible learning will continue to have an increasingly important role in higher education. Given the many fallacies about online learning, this paper argues that flexibility and transferability are prevailing traits in this explosion of knowledge. There is, simultaneously, a growing concern that online or flexible education has not raised learners' level of abstraction. This paper concludes with a call for further investigation into flexibility/transferability and the effectiveness of institutions to align faculty development models and infrastructure with the new science of learning as well as to equip faculty with techniques to enhance level of abstraction.
\end{abstract}

\section{INTRODUCTION}

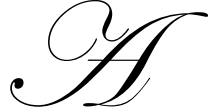

commonly accepted definition of flexible learning is that students have access to learning experiences in: time, place, pace, learning style, content, assessment, and pathways (Chen, 2003). Flexible learning is founded in the ideology that learning requires active engagement of students. That is, lasting learning is built from concepts that students construct their own meaning for; concepts that become part of the student's schema are more likely to transfer to new problems and settings or result in meta-cognition (Donovan, Bransford, \& Pellegrino, 1999). The new science of learning also purports that uncovering students' preconceptions about a concept leads to deeper understanding. Other characteristics of flexible learning include collaboration with peers and/or practitioners, that learning is contextualized, and the shift of the teacher's role is towards facilitator (Chen, 2003) a methodology that could be named social constructivism.

Critics of flexible learning call it just another fad (Zemsky \& Massy, 2004). These criticisms are founded in claims that online learning failed to launch a pedagogical revolution or attract students in masses. Few of the virtual universities struck it rich and many were not able to sustain. Reports of companies like Intel ending its employee relationship with the University of Phoenix over accreditation issues makes you wonder what will become of for profit institutions (Woo, 2007). Part of the problem is that from the very start few universities based their online ventures on solid business plans (Oblinger \& Hawkins, 2005). So little was known about what it would take to support online learning; exigencies placed on universities to support online learning put their own programs at risk. Although it is not all bad news, the success of University of Massachusetts online could very well be related to their motto "Because Quality Matters" as well as their pricing structure and the value students get for it. University of Massachusetts applicants have the same admissions review as on ground students adding to the quality of the student it attracts and their overall success. 
With all the buzz of successes and failures, flexible learning will continue to have an increasingly important role in higher education. Situations often reverse themselves due to changes in demographics or adoption rates of technology; institutions need to have tolerance for ambiguity along with the ability to flex up or down with the needs of the population. According to a 2005 national survey conducted by Eduventures, 10\% of the 18-24 age group, 20\% of the 25-34 age group, and 30\% of the 35-55 age group would consider enrolling in online courses and 20\% of the 18-24 age group say they are interested in hybrid courses (Eduventures, 2005). Public universities like Pennsylvania State University have 5,691 students taking online courses. The University of Massachusetts has 9,200 that are mostly working adults in masters programs between the ages of 25 and 50, and $30 \%$ are out of state (Golden, 2006).

Given the many fallacies about online learning, this paper argues that flexibility and transferability are prevailing traits in this explosion of knowledge. Through this literature review, the beauty and the underpinnings of flexibility in online teaching and learning are clear. This paper concludes with a call for further investigation into flexibility/transferability and the effectiveness of institutions to align faculty development models and infrastructure with the new science of learning with a clear eye to avoiding training and moving into the realm of abstraction truly worthy of the name Education.

\section{THE PROBLEM OF ABSTRACTION}

Abstraction is the ability to "net" an article which, in effect, is the summation of the initial ideas contained in a concept. The first order thinking is contained in the syllabus with definitions, etc. while the second order of thinking attempts an application of the definition to other ideas. For example, in first order thinking the question is: Can I apply this idea to something else? While the second order level of thinking attempts seeing relationship between one idea/object and another (e.g. does the Y chromosome require hair?). Third order thinking involves problem solving or notating of discontinuities such as the question: is violence caused by Y chromosome? Finally, the fourth order of abstraction seeks to project the concept or idea into an unknown set. To summarize: First Order is given in syllabus (e.g. topics); Second Order involves the applications of topics and conceptual understanding of its content. The third order is what flows from second order and involves identification of problem sets and exceptions. Finally, the fourth order involves vision such as: What conditions must be satisfied to apply to an unknown set?

An Example will clarify. Let us consider the subject of Ethics. First Order: Definition of the subject matter; Second Order: Why needed? (common rules, etc.); Third Order: Where applied? Fourth Order: Universal domain of ethical rules.

\section{Example 1: Math}

- $\quad$ First Order: topics/definitions

- $\quad$ Second Order: Development of theorems and applications

- $\quad$ Third Order: Propositions

- $\quad$ Fourth Order: A calculus universally applied.

In an online environment it is, I believe, more challenging to achieve these stages of conceptual abstraction on the part of the learners. Order one is found in the syllabus definitions while order two is attempted by application exercises but because of a-synchronicity, application exercises are not clarified immediately. Therefore, the third order has a higher probability of misapplication. Finally, the fourth order, given accumulation of errors, results in projections having a higher probability of significant flaws.

Potential Remedies include newly developed techniques/technologies which support mentor interventions and learner interaction. These include the use of cameras, chats, Eluminate and conferencing which permit real-time interactions. While important feedback such as body language is diminished, some clearer interaction patterns can be assured. 


\section{THE BROADER CONTEXT: RESPONSIVENESS OF THE INSTITUTION TO THE LEARNING COMMUNITY}

Clearly institutions whether they offer wholly online programs or not, ought to be responsive to the needs of learners, which are changing due to economic, social, political and technological developments (Cornish, 2004). The shift from information age to interaction age is particularly relevant to education (Milne, 2007). Students require learning that is interactive, mobile, continuous, and adaptable. Students expect learning approaches that reflect the demands of their work and lifestyle; mandatory classroom learning is becoming less appropriate. In a traditional lecture, information retention was shown to decline substantially after approximately ten minutes (Thomas, 1972). Therefore, one common flaw with traditional lecturing is that since it relies solely on the professor delivering information for a definite period of time and not necessarily receiving feedback on how that information is being received, it often adequately fails to involve the students. The result is that many students fail to pay attention and therefore have difficulty learning the material. A recent study by the National Center for Research to Improve Postsecondary Teaching and Learning comparing the effectiveness of the dueling methodologies concluded that "experiments involving measures of retention of information after the end of a course, measures of problem solving, thinking, attitude change, or motivation for further learning, the results tend to show differences favoring discussion [student involvement] methods over lecture" (McKeachie, 1987, p. 70).

Flexible learning is also pushing institutions to adapt their policies and processes to align with accelerated learning, stretched out degree plans, blended courses, and online learning opportunities. Many institutions are rethinking how calendars and credits can be configured to accommodate flexible learning. It will be interesting to see how degree plans adapt to the increasing number of working students across the age spans. Will there be interest by the 18-25 age group in stretching out their education due to other commitments? There are few five-year undergraduate "degree plans" to choose from and these types of plans along with the benefits flexible learning affords may be a way to revive enrollment in the STEM disciplines: science, technology, engineering, and math. A drop in part-time enrollment is calling for institutions such as the University of California to look into providing a variety of degree plans for students to choose from and to design them programmatically (Fischer, 2007).

Furthermore, students require guidance to help them adapt to their roles as lifelong, autonomous learners. They belong to many social groups, yet they are still very much focused on the individual and need to be guided to work collaboratively and manage tasks. Students may be coming from a background where their parents did most everything for them or conversely one where they were responsible for an aging or disabled family member. The emerging generations of learners, no matter how mature or technically adept they may be, need mentoring and direction. "All genuine learning is active, not passive. It is a process of discovery in which the student is the main agent, not the teacher" (Adler, 1982). There is also an adjustment period for anyone new to online learning including instructors and students and these novices do better when they receive coaching about how to learn or teach online (Stodel, Thompson, \& MacDonald, 2006).

Flexible learning requires a well oiled/synergistic infrastructure and puts pressure on administration to have strategic plans in place and be responsive to the technological needs of their learning community. Supply of bandwidth and how the traffic is prioritized on those lines is a hot topic amongst users and policy makers, as is appropriate staffing levels to provide technological resources and development. Online courses also rely on an "always on" ideology (with some planned interruptions) and that adds another level of accountability on the infrastructure. Flexible learning seemingly drives the demand for emerging technologies, which in turn creates a need for skills to manage and support it. Institutions that standardize platforms and develop human metrics for their own accountability should know how better to spend up or down on supporting their infrastructure and be able to measure if they are getting the intended return on investment. It should not be overlooked that institutions have to have most of these resources whether they offer online courses or not, so it is to their advantage to try to use them to grow new markets (Meyer, 2006). 


\section{TRANSFERABILITY}

Institutions and collectives that standardize core tools for learning (while providing these resources on separate pipes/instances) stand to benefit from transferability. Core functionality includes an electronic grade book, assessment engine, and collaboration tools (synchronous and asynchronous). Using the same course management tools for on ground and online spurs the development of faculty collaboratives and support groups for sharing pedagogies made possible by technological progress. The same knowledge base can be used to support the learning community. Although course management systems alone have not gained us much in aligning teaching with the science of how people learn (Zemsky \& Massy, 2004), there may be answers found in the new Web.

Thanks to companies like Google who have opened up the programming interfaces of their applications, the new Web affords us the ability to write to it without having specialized skills and the growing numbers of free and low cost applications on the Web are catching on in higher education. These shiny and easy to use applications are becoming increasingly popular as teaching and learning tools (http://www.flixn.com/, http://www.writeboard.com/, http://pbwiki.com/). The beauty of these new tools is that they allow users to manage knowledge online, model solutions, communicate with voice and video, and collaborate on and use information in new ways (Maloney, 2007). Users should be aware that the shelf life of their creations made from these free tools could be short unlike university-supported applications that are mandated to remain in production. Ideally, institutions will be able to integrate a set of these flexible Web parts that are appropriate for education into their learning portal so that they become university supported; keeping the familiar parts running while adding emerging tools. These flexible Web applications in the form of wikis and blogs make it possible for students to bring their ideas into the learning space.

The higher cost of developing flexible learning is increasingly a hot topic in higher education. An intricate cost analysis conducted in Australia (Ling, Arger, Smallwood, Toomey, Kirkpatrick \& Barnard, 2001) shows that while the total cost for an on ground course is $A \$ 30,000$ per course per year, the flexible learning format costs $\mathrm{A} \$ 70,000$, if it runs as a one year project or $\mathrm{A} \$ 61,000$ per year if the projects spans over three years, more than twice the cost of on ground. In order to sustain the viability of flexible learning, there needs to be an initiative to have the same courses serving more students. Zemsky in 2004 said "The dirty little secret about giving professors incentives to teach online is that they go out and develop a course, they teach it for three years, and then they get tired of it - been there, done that. It is just wasted money. Therefore, the first thing that has to happen, which is difficult, yet what the University of Phoenix does, is to remove the course from faculty ownership. Colleges should build collectives to develop and teach the course." (18)

The cost of online learning need not be taken as an argument for eliminating flexible methodology or removing faculty from the development process. In fact, faculty commitment to flexible learning and transferability is critical. Ideally, learning is developed so that it can be used multiple times in different modalities and improves iteratively. Faculty who develop a course and teach it, are more vested in the course and have their head around the logistics of the course; courses that are highly interactive require that the faculty have a keen sense of where facilitation is needed. Faculty who step in to teach a course that they have not developed, shadowed, or communicated with the developer, undergo a greater adjustment period before they can teach the course effectively. At the same time, faculty understands that a course has to be designed in a way that if they go on sabbatical or the number of sections increase, the course can be taught by other faculty. If the faculty does not accept that ideology or perceives the upfront design of curriculum as inflexible, they should not be engaged in a course development contract and these expectations have to be understood before the process begins. Deliberate processes where faculty partner with an instructional designer, other faculty or subject matter experts are most effective. It is good to have a department chair review the proposal and course to assure that the course objectives are satisfied and that the methodology is appropriate to the discipline. Additionally, it is important that the faculty design the course in a way that students will be able to see the correlation between success in the class and success in the "real world". Students who view a link between the attainment of skills in a class and career growth are more likely to develop deep study habits than students who do not see the link (Lowman, 1990). While extrinsic methods still can be used to increase student motivation in the class, students who are intrinsically motivated are more likely to work harder than those 
who are extrinsically motivated. As a result, those students who are intrinsically motivated are more likely to achieve higher grades than the students who are extrinsically motivated (Dev, 1997).

Demand on faculty time is another factor that should not be overlooked. From my own data collection, I found that the time it takes to develop a course is approximately the time it takes to teach a course or 80 hours. Institutions might consider basing their compensation structure for development on what they pay for an adjunct teaching stipend, around $\$ 3000.00$. A study on the time it takes to teach or fulfill the facilitator role in an online course (Lazarus, 2003) shows that it takes about 5 to 7 hours a week in a 14-week course to respond to and grade 20 students on average. These hours do not include development of course content since that is done ahead of time. The increase in demands placed on faculty time is offset by the decreased time faculty must spend in research or to prepare for classes. Electronic communication among scholars, online journals, electronic publishing, or review of articles in traditional journals via the Internet are among the many ways in which information technology is saving researchers time and making their work more efficient.

\section{SUMMARY AND CONCLUSION}

The discussion in this paper is summarized in these main points:

- Online or Flexible learning means that students have access to learning experiences in: time, place, pace, learning style, content, assessment and pathways.

- $\quad$ Although online provides considerable access and convenience to learners, there remains the problem of raising the level of abstraction in the online environment which is more challenging than in the face to face, synchronous environment.

- With the addition of Eluminate, chats, and telephone conference calling interfaced with videoconferencing, some movement has been achieved to enhancing abstraction.

- $\quad$ Faculty commitment and cooperation is critical to the success of transferability of programs and courses as well as facility in critical thinking.

- $\quad$ Flexible learning requires a responsive infrastructure and additional resources

- Increasingly, students require learning that is interactive, mobile, continuous, and adaptable.

It follows that flexible learning is a methodology that higher education may use to meet their goal of providing quality courses and programs. Should institutions want to increase flexibility, they are wise to be cautious and flexible and to stay open for new developments, as new techniques and practices emerge that can improve efficiency and effectiveness of the development of online learning (Meyer, 2006).

There are clear indications that flexible learning requires more resources. However, there is little research on the effectiveness of flexible learning. This paper concludes with a call for further research into professional development models and their alignment with constructivist principles of learning. The envisioned research would include training in philosophy as a technique of intervention; re-vitalization of the Socratic method; and some concession to real-time interactions and interventions as well as the development of more abstract resources to force more in-depth analysis.

\section{REFERENCES}

1. $\quad$ Adler, M.J. (1982). The Paideia proposal: An education manifesto. NY: Macmillan.

2. Chen, D. T. (2003). Uncovering the provisos behind flexible learning. Educational Technology \& Society, 6(2), 25 - 30. Retrieved April 3, 2007, from Wilson Web.

3. Cornish, E. (2004). Futuring: The exploration of the future. Bethesda, MD: World Future Society.

4. Dev, P.C. (1997). Intrinsic motivation and academic achievement: What does their relationship imply for the classroom teacher? Remedial and Special Education, 18(1), 12-19.

5. Donovan, S. M., Bransford, J. D. \& Pellegrino, J. W. (1999). How People Learn: Bridging Research and Practice. Retrieved March 19, 2007, from http://books.nap.edu/openbook.php?isbn=0309065364. 
6. Eduventures. (2005) Assessing consumer attitudes toward online education. Boston, MA: Eduventures, LLC.

7. Fischer, K. (2007) Part-time enrollments drop in California. Chronicle of Higher Education, 53, 30. Retrieved April 3, 2007, from Wilson Web Omni file Full Text Mega Database.

8. Golden, G. (2006). Online university enrollment soars. Wall Street Journal. Retrieved April 7, 2007, from Proquest database.

9. Lazarus, B. D. (2003). Teaching course online: How much time does it take? Journal of Asynchronous Learner Networks, 7, 3. Retrieved April 5, 2007, from http://www.sloan-c.org/publications/jaln/index.asp.

10. Ling, P., Arger, G., Smallwood, H., Toomey, R., Kirkpatrick, D., \& Barnard, I. (2001). The Effectiveness of models of flexible provision of higher education. Retrieved April 7, 2007, from http://www.dest.gov.au/highered/eippubs/eip01_9/default.htm.

11. Lowman, J. 1990. Promoting motivation and learning. College Teaching 38(4), 136.

12. Maloney, E., J. (2007). What Web 2.0 can teach us about e-learning. Chronicle of Higher Education, 53, 18. Retrieved April 5, 2007, from Wilson Web Omni file Full Text Mega Database.

13. McKeachie, W.J., Pintrich, P.R., Lin, Y.G., \& Smith, D.A. (1987). Teaching and learning in the college classroom: A review of the literature. Ann Arbor: National Center for Research to Improve Postsecondary Teaching and Learning, The University of Michigan.

14. Meyer, K. (2006) Cost-efficiencies in online learning. Association for the Study of Higher Education. Retrieved April 3, 2007, from Wilson Web Omni file Full Text Mega Database.

15. Milne, A.J. (2007) Entering the information action age: Implementing a future learning vision for college campuses today. Educause Review. Retrieved April 5, 2007, from http://www.educause.edu/ir/library/pdf/ERM0710.pdf.

16. Oblinger, D. G. \& Hawkins, B. L. (2005). The myth about e-learning. Educause Review. Retrieved April 3, 2007, from http://www.educause.edu/ir/library/pdf/ERM05411.pdf.

17. Stodel, E. J., Thompson, T. L., \& MacDonald C. J. (2006). Learners' perspectives on what is missing from online learning: Interpretations through the community of inquiry framework. International Review of Research in Open and Distance Learning, 7, 3. Retrieved April 3, 2007, from Wilson Web Omni file Full Text Mega Database.

18. Thomas, J. (1972). The variation of memory with time for information appearing during a lecture. Studies in Adult Education, 4, 57-62.

19. Woo, S., (2007) Intel cuts 100 colleges from its tuition-reimbursement program for employees. Chronicle of Higher Education, 53, 22. Retrieved April 3, 2007, from Wilson Web Omni file Full Text Mega database.

20. Zemsky, R. \& Massy, W. F., (2004). Thwarted innovation: What happened to e-learning and why. Retrieved March 30, 2007, from the University of Pennsylvania, The Learning Alliance for Higher Education, http://www.irhe.upenn.edu/WeatherStation.html. 